\title{
The Hegelian critique of Kantian antinomies: an analysis based on the Wissenchaft der Logik
}

\author{
Marcos Fábio Alexandre Nicolau, José Edmar Lima Filho \\ State University of Vale do Acaraú, Sobral, Brazil \\ Email address: \\ marcosmcj@yahoo.com.br (M. F. A. Nicolau), semedmar@yahoo.com.br (J. E. L. Filho)
}

To cite this article:

Marcos Fábio Alexandre Nicolau, José Edmar Lima Filho. The Hegelian Critique of Kantian Antinomies: An Analysis Based on the Wissenchaft der Logik. International Journal of Philosophy. Vol. 1, No. 3, 2013, pp. 47-50. doi: 10.11648/j.ijp.20130103.12

\begin{abstract}
Our work aims to analyze Hegel's critique on the Kantian antinomies in his Wissenchaft de Logik. For Hegel, the metaphysics that presents the true nature of things is the metaphysics of contradiction. By identifying his Logic with this metaphysics, he intended to present in this work the immanent determinations to thought, hence the denomination logic of contradiction. On this account, he will impose corrections to Kantian antinomies, albeit he praises the initiative of the philosopher from Königsberg of turning his attention to the dialectics.
\end{abstract}

Keywords: Hegelian Dialects, Kantian Antinomies, Logic of Contradiction

\section{Introduction}

As the first major development of the Hegelian logic occurs on the identity of metaphysics with logic, the second development relates to the element of contradiction itself. It is known that Hegel introduces his discussions on conflict through a consideration of the Kantian antinomies. For each one of the four Kantian antinomies, two opposing propositions are asserted concerning the same object, and it is shown that each one of the opposing propositions must be asserted with equal need.

Thus, each antinomy puts a contradiction, which is why Hegel emphasizes the importance of exposure of the Kantian antinomies. But, according to him, Kant fails in two main aspects. The first lies on bringing out only four antinomies, which are derived fundamentally from the board of the categories. On the other hand, Hegel insists that contradictions are found in all types of objects and in all and any representation, concept or idea. For there is absolutely nothing, nowhere in which the contradiction cannot and should not be exposed. This can be understood in the consideration of another aspect in which, for Hegel, Kant fails as he refers to it as the "tenderness for the things of the world." "For him, the matter is that Kant takes contradictions as belonging not to the essence of things of the world, but only to the thinking reason.

In its turn, the linkage between denial, antinomy and

Unless otherwise noted, all translations are my own. system is the midpoint of Hegel's thought. The contradiction should be released not only beyond these four instances presented in the Kantian antinomies, but also beyond the mere thought, that is beyond our reason: the real objectivity of thinking is knowing that our thoughts are not merely our thoughts, but at the same time, thinking is the 'in-itself' of things and the objective being.

Hegel intends to give recognition to the instance of the contradiction at the core of world itself. So our proposal to analyze how Hegel understood Kant's antinomies of pure reason, and also how he suggested a new stance on the idea of contradiction to establish it beyond the subjective, gets its significance as it accurately elucidates the divergence between the two philosophical proposals which founded the contemporary thought.

\section{The Logic of Contradiction Versus the "Tenderness for the Things of the World"}

It is known that Hegel began to edit his Wissenchaft der Logik (1812) some 25 years after the second edition of the Kritik der reinen Vernunft of Kant (1787). For this reason, he could not fail to consider the lack of substantiation of the principles by which science begins, once it is necessary to exist some work previous to the principle, on its justification as a beginning. Thus, it is a mistake to care only about the principle without giving importance to the justified beginning. During that period, such mistake was 
made by those who would propose to start with the absolute, without making any reflection on this, regardless "of the method and logic."Due to Kant, philosophy gained constitution of a real critique of reason, i.e., a search for the validity on the procedures of this reason, developed through a radical critique of reason on itself. Considering it is easier to refute than to justify, Hegel reasoned that the effort should be that of establishing a justified beginning, a principle that must be the union of method and content, a principle that must also be united to form. Hegel takes on the task of building a prime foundation. This characteristic, typical of idealism, converts Wissenchaft der Logik in a real Wissenschaftslehre.

Noting the difficulties to which the subjective idealism was headed, Hegel takes over and assumes the identity of being and thinking, of finite and infinite. For Hegel this is the supreme law of the identity of all thought and all reality. Hence the reason why Hegel did not give up on this access to the unconditioned: it is the idea of a real absolute, which only is in its manifestation, which gives meaning to the dialectical process established in the Hegelian system. The absolute represents the true dialectical fulfillment of the identity between being and thinking.

It is specifically this importance given to the contradiction, - so radically assimilated by Hegel in his methods - the reason why he enforces corrections to the Kantian antinomies, even though he praised Kant's considerations on dialectic, as mentioned before. Even though these antinomies have a huge merit, his presentation is imperfect and mistaken with regards its result: presupposing that understanding only accepts finite categories as ways of thinking is one of the Kantian errors. On that account, in Hegel's comprehension, Kant's explanation of the antinomies should have a better criticism to elucidate his perspective and his method more precisely.

In order to put Hegel's critique in context, we recall the "antinomies of pure reason" ( $K r V$, A340, B398), defined by Kant as the transcendental conflicts of ideas (cf. $\mathrm{KrV}$, A426, A461, B454, B489):

T1. The world has a beginning in time, and is also limited as regards space.

A1. The world has no beginning, and no limits in space; it is infinite as regards both time and space.

T2. Every composite substance in the world is made up of simple parts, and nothing anywhere exists save the simple or what is composed of the simple.

A2. No composite thing in the world is made up of simple parts, and there nowhere exists in the world anything simple.

T3. Causality in accordance with laws of nature is not the only causality from which the appearances of the world can one and all be derived. To explain these appearances it is necessary to assume that there is also another causality, that of freedom.

A3 There is no freedom; but everything in the world takes place solely in accordance with laws of nature.

T4. There belongs to the world, either as its part or as its cause, a being that is absolutely necessary.

A4. An absolutely necessary being nowhere exists in the world, nor does it exist outside the world as its cause.

For Kant, the theses are dogmatic propositions, not subject to experimental verification, which does not make them useless or superfluous. Its practical function is invaluable. The theses form the basis for religion and ethical behavior. On the other hand, the antitheses are to him purely empirical propositions and therefore would only be subject to experimental verification. Kant called them cosmological antinomies. They manifest themselves through the assumption that space, time and cause are external things, with no bounds to perception, which had been anticipated as a negative in the Analytics. Philosophy has to realize that these elements are not things, but modes of interpretation. Moreover, the principle of pure reason whenever it is "given the conditioned it is also given (that is, contained in the object and its connection) the whole series of subordinated conditions, series that are therefore unconditioned" (KrV, A307-308, B364) - can only be sustained on a foundation of fundamental distinction between what is the object itself and how it presents itself to us.

In this sense, despite the invitation to skepticism given the contradictions of reason with itself, Kant proposes the critical attitude of the revelation of what he calls transcendental illusion or appearance. For this reason, the philosopher of Königsberg announces as a duty of Dialectic "considered as a critique of the understanding and of reason relatively to its Hyperphysics use [...] - to unmask the false appearance of such baseless assumptions and reduce their claims of discovery and extension - of which the reason supposes to reach solely through transcendental principles - to the simple act of judging the pure understanding and warning it of sophistic illusions" ( $K r V$, B87).

As a result, whenever the reason applies principles that are valid exclusively to the phenomenical world into the noumenal world, it always falls into contradiction. It happens because in dialectical thinking - as in the antinomies, for instance - one would take into account two assumptions which correspond to two distinct areas: "the major premise of the cosmological argument of reason takes the conditioned in the transcendental meaning of the pure category, while the minor premise considers it within the empirical meaning of an understanding concept applied to simple phenomena [...]. There lies one dialectic error called sophisma figurae dictionis. This mistake, however, is not intentional. It is a very natural illusion of common reason, since we assume by it (in the major premise) its conditions and series, in a we did not notice it manner, when something is given to us as conditioned - and that is nothing more than the logical demand to admit full premises for a given conclusion - just as there is no order of time in the connection of the conditioned to its condition. They are assumed to be given simultaneously" ( $\mathrm{KrV}$, A499-500, B527-528).

As the first major development of the Hegelian logic 
occurs on the identity of metaphysics with logic, the second development relates to the element of contradiction itself. Not coincidentally Hegel introduces his discussions of the conflict through a consideration of the mentioned Kantian antinomies, well exemplified in what follows: "Kant raised the dialectic much more - and this is one of his greatest merits - for repaying the whole appearance of arbitrary act which it had due to its ordinary representation, and showed it as a necessary operation of the reason. However the dialectic was understood only as an art of creating mirages and raising illusions. It had been thought it simply played a false game and that all its strength was based only in hiding the fraud, that its results were surreptitious and of subjective appearance. Evidently, the exhibitions of Kant's dialectics, on the antinomies of pure reason, do not deserve much praise when examined carefully, as we shall explore with more breadth in the continuation of this work. Nonetheless, the general idea set by him as a foundation is the objectivity of appearance, and the necessity of contradiction, that belongs to the nature of the determinations of thought." ( $W d L 5 / 51$ )

Even so, Hegel does not leave to consider Kant's reflection as one of the deeper progresses of Modern Philosophy. For him, it was really important to point out the essential and necessary character of contradiction, although the Critique of Pure Reason represents this contradiction as something extrinsic to the concepts. With this, Kant did not recognize positive aspects of antinomies. He stayed in the negative result of things in-itself that cannot be known and he did not penetrate in the knowledge of real and positive signification of antinomies.

For each of the four Kantian antinomies, two opposing propositions are asserted with respect to the same object, and it is shown that each of the opposing propositions must be asserted with equal need ${ }^{2}$. Thus, each antinomy sets a contradiction, which is why Hegel emphasizes the importance of the Kantian display of the antinomies "These Kantian antinomies always remain an important part of the critical philosophy. They are especially responsible for the fall of the previous metaphysics and can be considered the main access route to modern philosophy. It has also contributed in particular to produce persuasion on the nullity of the categories of finitude on content issues. This is a more proper way than the formal one of a subjective idealism, according to which their defect should consist on their being in a subjective form, and not in what they are in themselves. However, despite its great credit, this exhibition is very imperfect" ( $W d L 5 / 215)$.

Yet, according to Hegel, Kant fails on two main aspects: the first is to bring out only four antinomies, which are derived primarily from the board of the categories. Hegel insists on a different perspective in which the antinomies

Of which Hegel presents an example in which it is stated that the world has and does not have a beginning in time and space limits, an issue set forth in the Propaedeutic (cf. Propädeutik, 4/183-191 ), and later in a statement of the Science of Logic itself on Kantian antinomies (cf. $W d L$, $5 / 270-5 / 275)$ are found in all types of objects, as well as in any representation, concept and idea. For there is nothing anywhere in which the contradiction, that is, opposite determination, cannot and should not be exposed, as explained in Enzyklopädie der philosophischen Wissenschaften im Grundrisse: "The main point to note is that the antinomy is not only in the four particular objects taken from Cosmology, but in all objects of all kinds, in all representations, concepts and ideas. Knowing this, and knowing the objects according to this property, is part of the essential of the philosophical consideration. This property constitutes what is later determined as the dialectical moment of the logic" (Enz., § 48, 8/126-127).

Therefore, Kantian antinomies - in Hegel's conception only comprehended opposite moments of the contradiction singly, namely, in face of the sole choice either... or..., such as antinomies, Hegelian dialects responds neither one thing nor the other, but a third, which corresponds to a change of perspective on the concept at issue (Aufhebung).

It can be understood when consideration of another aspect in which, for Hegel, Kant fails, characterized as the "tenderness for the things of the world". For him, the matter is that Kant takes the contradictions as belonging not to the essence of things in the world, but only to the thinking reason: "There is an excessive tenderness for the world in the act of removing its contradictions, transferring it to the spirit, the reason, and letting it stand there without solution" ( $W d L$ 5/275). The contradiction should be released not only beyond these four instances presented in the Kantian antinomies, but also beyond the mere thought, that is beyond our reason. Hegel expects the recognition of the instance of the contradiction at the core of world itself, as Kant does not seem to "realize that the contradiction is precisely the elevation of reason over the limitations of the intellect and their solution" ( $W d L$ 5/38).

In other words, Kant's transcendental idealism let the contradiction to subsist, under the comprehension that it is not the objective essence of things and ascribing antinomies to the subjectivity and not to the reality. For Hegel, the big problem is that contradiction is not resolved in this way. It subsists after as before.

For Hegelian critique, Kant's solution leaves the antinomies content out, because it does not reach to the nature of the concept, which is essentially the unity of opposites. Each one isolated in itself is null and is only determined when it pass over the other - this is reported by early dialectics in the Science of Logic of which the ceaselessly passing over of the being in nothingness, and vice versa, is suprassumed in the concept of there-being.

On Hegelian conception, every concept could offer its own antinomy and establish as many antinomies as concepts, which was comprehended by ancient skepticism: "The ancient skepticism spared no effort to show the contradiction, as well as the antinomies in all concepts found in Science".

Thus, in Hegelian perspective, it is obvious that the antinomies solution is in the "being-together" of opposites, 
whereas it is not worth assembling antinomies to show its apagogical nature, as Kant does, because no antinomy let itself to be assembled, it simply is.

\section{Conclusion}

There is contradiction in all things, for "the contradiction is the root of all movement and vitality, because only in when it has something in itself, a contradiction gets to have movement, impulse [Trieb] and activity [Tätigkeit]" (WdL 6/74).

Thus, the metaphysics that shows the true nature of things is the metaphysics of contradiction. Logic, which - as already mentioned - is identified with such metaphysics, presents its own determinations immanent to the thought. For this reason, it is called the logic of contradiction.

Hegel replaces the traditional logic of Aristotelian root, which would borrow from the metaphysics the principle of non-contradiction and turn it into the fundamental principle to which all logical transition would be required to join $-\mathrm{a}$ new logic, targeted precisely at the thought of the contradiction, a logic that would assert such a thought, a logic that fully recognizes that "it is ridiculous to say that the contradiction cannot be thought" (WdL 6/74).

\section{References}

[1] HEGEL, G. W. F. Werke - Herausgeber Hegel-Institut Berlin. Berlin: Talpa-Verlag, 1998 (CD-ROM).

[2] Wissenschaft der Logik. In: Hegel Werke - Herausgeber Hegel-Institut Berlin. Op. cit.

[3] Texte zur Philosophischen Propädeutik. In: Hegel Werke Herausgeber Hegel-Institut Berlin. Op. cit.

[4] Enzyklopädie der philosophischen Wissenschaften im Grundrisse. In: Hegel Werke - Herausgeber Hegel-Institut Berlin. Op. cit.

[5] KANT, I. Kritik der reinen Vernunft. Hamburg: Felix Meiner, 1990. 